\title{
The Walden Inversion, a reply to a paper by Prof. P. Karrer and W. Kaase
}

by

G. W. Clough.

(19. I. 20.)

More than six years ago I commenced an investigation with the view of ascertaining whether a study of the influence of solvent, concentration and temperature on the optical rotatory piowers of certain similarly constituted compounds possessing the same relative configurations would reveal regularities which could be subsequently utilised for the determination of confinurative relations in doubtful cases ${ }^{1}$ ). A comparison of the optical rotatory powers of th. configuratively similar hydroxy-acids usually denoted l-lactic acid, l-glyceric acid, d-malic acid, d-tartaric acid and of derivatives from them led me to assume: that the optical rotatory powers of similarly constituted compounds possessing the same relative configurations are, in general, influenced similarly by the same changes in the external conditions and also by the introduction of the same substituent into a given radical attached to the asymmetric carbon atom. The application of this rule made it possible to draw the following conclusions:

1. d- $\alpha$-0xybutyric acid, d- $\alpha$-oxyglutaric acid etc. possess the same configurations as l-lactic acid, d-tartaric acid etc.

2. The naturally occurring $a$-amino-acids are all configuratively similar to one another.

3. The dextrorotatory $\alpha$-halogen acids which have been isolated are contfiguratively similar to one another.

4. The naturally occurring $\alpha$-amino-acids are related configuratively to the dextrurotatory $\alpha$-halogen acids.

I also suggested that the $\alpha$-hydroxy-acids configuratively related to d-tartaric acid are enantiomorphously related to the natural $\alpha$-amino-acids and therefore also to the dextrorotatury $a$-halogen acids.

Quite recently $P$. Karrer and $W$. Kaase ${ }^{2}$ ) have published the results of an examination of the optical rotatory dispersions of some derivatives of succinic acid and glutaric acid. These investigators have made certain deductions concrrning the configurative relations of the compounds in question and have criticised the views which they bclieve I have expressed. Karror and Kaase attribute to me the opinion that "die natürlichen Aminosäuren, die oben erwähnten Oxysäuren und dje rechtsdrehenden $a$-Ilalogensäuren sind konfigurativ alle gleich" ${ }^{3}$ ) and further state that the configurative relations they have deduced from a study of the rotatory dispersion curves of d-a-oxyglutaric acid, d-glu-

1) Soc. 105,49 (1914); 107, $96,1509(1915) ; 113,527$ (1918).

2) Helv. 2, 436 (1919). 3) p. 440. 
tanic acid and l-chloroglutaric acid are in agreement with this view. The suggestion I actually made was that the dextrorotatory halogen acids possess configurations opposite to those of the $\alpha$-hydroxy-acids l-lactic acid, d-tartaric acid etc. The conclusions of karer and katse in connexion with the optically active derivatives of glutaric acid are therefore not in conformity with those which I have drawn.

The same investigators make the statements: "Clough ist der Ansicht, dass Phosphorpentachlorid und Thionylcblorid aus aliphatischen $\alpha$-Oxysäuren ohne Konfigurationsänderung die entsprechenden $\alpha$-Chlorcarbonsäuren erzenge. Dagegen soll bei der Einwirkung von Nitrosylchlorid auf $\alpha$-Aminosäuren und bei der Einwirkung von Silberoxyd auf $\alpha$-Chlorcarbonsäuren Konfigurationswechsel Platz greifen". Curiously enough these statements are in direct contradiction to the ideas which Karrer and kaase have previously ascribed to me, but in spite of this fact, they do not accurately represent my opinion. I have not stated that by the action of silver oxide on optically active aliphatic $\boldsymbol{\alpha}$-halogen acids, a configurative change invariably occurs, but I maintained that the scheme ${ }^{1}$ ) includes "must of the changes which have so far been realised with $a$-derivatives of propionic acid, hutyric acid, succinic acid, isohexoic acid and $\beta$-jhenylpropionic acid" (not glutaric acid). It is thus unnecessary for me to reply to the criticisms made by $k^{\prime} a$ wr and kaase which are based on a misronception of my views.

Notwithstanding the fact that the deductions made by Karrer and Kaase from their rotatory dispersion curves are, in the case of derivatives of sucrinic acid, in complete harmony with $\mathrm{my}$ conclusions, I am unable to agree with these authors that their experimental observations necessarily lead to the stereochemical relationships which they have adopted. For example, no reason is advanced by Karrer and Kaase for the selection of the rotatory dispersion curve for ethyl l-aspartate constructed from the rotations of this ester in ethyl alcoholic: solution (in which solvent the rotation increases positively as the wave-length diminishes) rather than that which might be constructed from the values which I have published ${ }^{2}$ ) for the homogeneous ester (which shows a maximum laevorotation in the violet region of the spectrum). It seems possible that a useful comparison of rotatory dispersion curves might be made if the rotatory powers were measured under conditions such that the substances exhibit the phenomenon of anomalous rotatory dispersion, but hitherto this phenomenon has not been observed in the case of halogen acids or esters. The method employed by Karrer and Kause appears to be, a special application of the suggestion of Pickard and Kenyon ${ }^{3}$ ), who, having shown that the rotatory dispersive powers of a large number of configuratively similar derivatives of a parent compound may be correlated on one "characteristic diagram" 4), propose the employment of such a diagram for the determination of the relative configurations of other derivatives of the compound. Much experimental work on the optical rotatory dispersive powers of optically active compounds under
1) Soc. 113, $550(1918)$.
2) 1). 553 .
3) Sor: 105, 846 (1914).

1) Proc. Ror. Sor., A, 88, 389 (1913). 
varying conditions is necessary before we can trace the relative effects of the groups attached to an asymmetric carbon atom and thus be able to deduce with certainty configurative relationships from optical rotatory powers.

In conclusion, it seems very undesirable, in the present state of cur

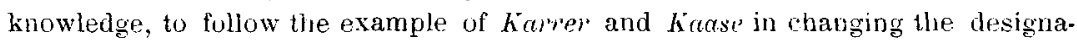
tions of ordinary malic and aspartic acids from 1- to d-. Experience shows that the confusion which would result from such a change would far outweigh any temporary advantage.

The College of Technology, Manchester. January 14, 1920.

\section{Sur les acides 0 - et p-nitro- $\alpha$-bromocinnamiques par}

\section{S. Reich $\dagger$ et N. Y. Chang.}

(26. I. 20).

Les acides nitrobromocinnamiques répondant aux formules suivantes:<smiles></smiles><smiles>O=C(O)C#CC1CCCC([N+](=O)[O-])C1</smiles><smiles>O=C(O)C=CC1CCC([N+](=O)[O-])CC1</smiles>

doivent théoriquement pouvoir exister en deux modifications stéréoisomériques différentes. Les deux modifications de l'acide méta ont été décrites par l'un de nous ${ }^{1}$ ). Celles de l'acide para ont été obtenues par Mïller ${ }^{2}$ ) en faisant agir la potasse alcoolique sur l'éther p-nitrophényl-dibromopropionique, mais avec un rendement très faible. Quant à l'acide ortho, on n'en connaît qu'une des modifications; elle a été préparée par $\mathrm{Naar}^{3}$ ) par une voie dẻtournée et peu pratique.

Cherchant à combler ces lacunes, nous avons trouvé que les rendements, dans la préparation de ces acides, deviennent

1) S. Reich, Arch. lien. (4) 45, 191 (1918)
2) A. $212,122(1882)$.
3) B. 24, 251 (1891). 